\title{
せん断流中における単一気泡の三次元形状変化と周囲流動構造 （気泡形状の非対称性と渦放出の関係） \\ Rising Bubble Three-Dimensional Deformation and Flow Structure in a Linear Shear Flow (Relation between Asymmetry of Bubble's Shape and Shedding Vortex)
}

\author{
○学 坂田 矢亜土（慶大院）段本 由紀（リコー） 正 藤原 暁子（東大 IML） \\ 正 菱田 公一（慶大理工） \\ Yaado SAKATA, and Koichi HISHIDA, \\ Dept. of System Design Eng., Keio Univ., 3-14-1 Hiyoshi, Kohoku-ku, Yokohama, 223-8522 \\ Yuki DANMOTO, RICOH, 1-15-15 Minamiaoyama, Minato-ku, Tokyo, 107-8544 \\ Akiko FUJIWARA, Intelligent Modeling Laboratory, the Univ. of Tokyo, 7-3-1, Hongo, Bunkyo-ku, Tokyo 113-8564

\begin{abstract}
The dynamics of a single, rising air bubble in a linear shear flow was investigated by high speed and high spatial resolution CCD cameras in a vertical water channel. The present study focused on the influence of forces acting on the bubble and its lateral motion induced by the surrounding flow field. The flow structure in the vicinity of the bubble of 2 to $6 \mathrm{~mm}$ in diameter was obtained by a PIV/LIF technique, and deformation of the bubble's interface was measured by a shadow imaging technique. It is found that the bubble trajectory was mainly affected by the three-dimensional vortex shedding in the wake. Experimental data of the averaged vorticity at the edge of bubble, the bubble aspect ratio and the curvature of bubble edge showed that the magnitude of vorticity correlates with the bubble shape.
\end{abstract}

Key Words: Bubble Deformation, PIV/LIF/SIT, Lateral Motion, Vorticity at the Edge of Bubble, Curvature

\section{1. 鼓四}

本研究は気泡の形状変化と周囲流動場の相互干涉の微視 的理解を目的とする. 気泡の形状と運動に関して過去にも 多く研究がなされ整理されているが(1)(2)，その詳細な変動 や非対称性に触れたものは未だ少ないのが現状である。そ こで本研究ではせん断流中に、ジグザグ運動を有する 2 6 $6 \mathrm{~mm}$ 程の気泡を上昇させ, 周囲流動構造と二方向から の形状投影の同時計測を行った．相互干涉を支配する重要 な要素として, 三次元的な気泡位置・形状（気泡の重心位 置とアスペクト比, エッジ部曲率) の変動, 二次元断面に おける流動構造, 特にエッジ部における渦度に注目し, そ の面積平均値の変動を追った。これより瞬時の, 気泡重心 位置に対するアスペクト比, 曲率, 及び渦度の相関を探る。

\section{2. 计測方法}

Fig.1 に実験装置及び計測装置概略図を示す. 計測には三 台の高速度·高空間分解能 CCD カメラ $(500 \mathrm{~Hz} \cdot 1260$ pixel $\times 900$ pixel）を用いた。周囲流体の流速計测には営光粒子を トレーサとした PIVを, 気泡形状撮影には赤外線及び青色 LED 群を光源とした投影法を用いる. この時, 各カメラに おいて所望の情報のみを得るため, 光学フィルタによって 波長を分離し撮像した. 形状は直交する二台の CCD カメ ラにより撮像し，二方向からの気泡投影図を時系列で得る. また三台の CCD カメラと各光源は照射タイミングを同期 させており，流動場と気泡形状の同時計測が可能となる.

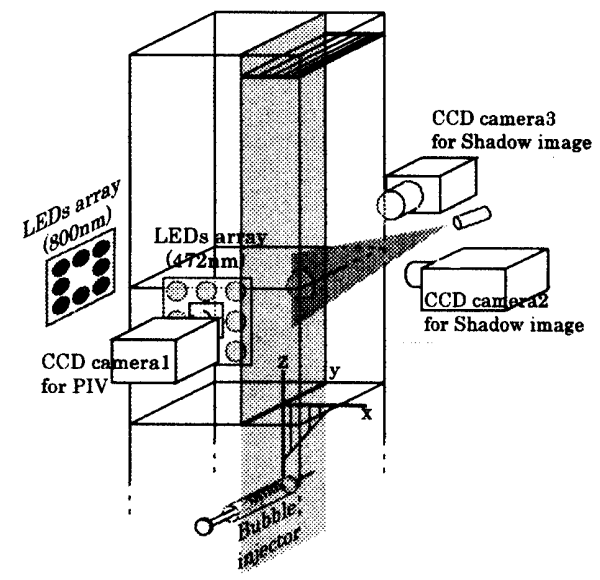

Fig. 1. Experimental setup

\section{3. 实䀶方法}

実験流路はアクリル製チャネルである．チャネル入口の ノズルは非対称形をしており，局所一様下降せん断流を形 成させる.この単相時(液相)平均流速分布 $W_{l}[\mathrm{~mm} / \mathrm{sec}]$ を Fig. 2 に示す. 計測領域におけるせん断率は $1.2\left[\mathrm{~s}^{-1}\right]$ となっ た. またテストセクションは幅 $h=50 \mathrm{~mm}$ ，奥行き $100 \mathrm{~mm}$ であり，座標系位置は $h$ を用いて無次元化した。ただし座 標系は気泡注入位置の高さで壁面中央を原点とし, 流れと 垂直に赤外 LED から CCD カメラ 2 に向かう方向を $x$, 奥 行き方向を $y$, 流れ方向上向きを $z$ とする.

実験条件を Table 1 に示す. $M$ はモルトン数で左より面 積等価直径, 相対速度, 気泡レイノルズ数, エトベス数, アスペクト比となっている。
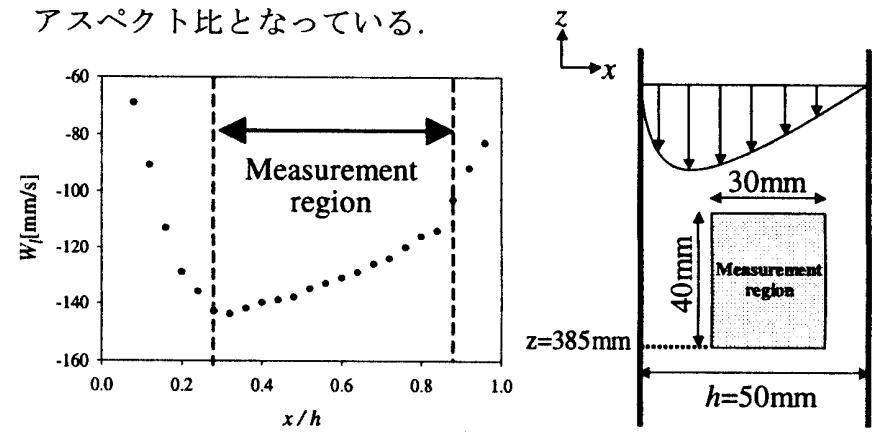

Fig. 2. Velocity profile in single phase and position of the measurement region

Table 1. Experimental conditions $\left(M=7.70 \times 10^{-10}\right)$

\begin{tabular}{|c|c|c|c|c|}
\hline$D_{e q}[\mathrm{~mm}]$ & $W_{\text {rel }}[\mathrm{mm} / \mathrm{s}]$ & $R e_{\text {rel }}$ & $E o$ & $A s$ \\
\hline 4.59 & 260.23 & 594.01 & 3.43 & 0.70 \\
\hline 3.52 & 266.81 & 467.25 & 2.02 & 0.74 \\
\hline
\end{tabular}

\section{4. 結果及び者霖}

\section{1 気泡の上昇轨道と洞度分布}

気泡の上昇軌道は，本実験条件においてジグザグ運動を 示した. その様子を Fig. 3 に示す. しかしながらジグザグ 運動の方向はほぼランダムであり，ジグザグ運動を行う面 によって周囲渦度場に違いが現れた. その様子を Fig. 4 に 示す. Fig. 4 a)は主に $x-z$ 平面においてジグザグ運動を行 う場合，b)は $y-z$ 平面において行う場合である. a)ではジ 
グザグの進行方向が変わる際, 気泡後流部に渦放出が左右 エッジ部から交互に起きている様子が見て取れた，b)では 左右対称の渦放出が起きている. すなわち気泡のジグザグ 運動の方向に対して切り取る後流断面が異なるために, 捉 えているへアピン渦の断面(3)が異なって渦構造も観察され ている．またこの時 Fig. 4a)，b)からも判るように，ジグザ グ運動を行う面における気泡の投影形状は非対称性を示し ている。これは左右交互に渦放出が起こる為に気泡のエッ ジ部における圧力分布が対称でないためである.

\section{2 気泡の形状変化}

前項を踏まえ, 気泡形状(アスペクト比 As と左右エッジ 部の曲率 $k_{L}, k_{R}$ の比 $\left.k_{f}=k_{L} / k_{R}\right)$ の周期変動の側面から考察を 行う。曲率は Fig.5 のように気泡長軸端での界面形状の曲 率である.Fig. 6 に気泡重心位置 $x_{c} / h$ と As の変動, 及び Fig. 7 に $x_{c} / h$ と $k_{f}$ の変動を示す.これより $x_{c} / h$ の周期は $A s$ の周 期のおよそ 2 倍になっていることが判る.また $x_{c} / h$ が極值 に達したときに As が低くなり， $x_{d} / h$ が中間の位置では $A s$ が大きくなっており, ジグザグの進行方向が変わる瞬間に 最も扁平になっている．さらに $k_{f}$ は $x_{d} h$ と位相がずれた状 態で同周期にて変動し， $x_{c} / h$ が極值に達した時に 1 に近い 值を取り対称な形状となる． $x_{c} / h$ が中間の位置では $k_{f}$ の変 動が極値となっており非対称形状となる。したがって気泡 の形状変化は本実験条件にて Fig. 8 のように変動する.

\section{3 気泡エッジ部洞度の变動}

気泡形状と周囲流動場の状態は共に変動する事が示され た. そこで本研究では気泡エッジ部において半径 $1 \mathrm{~mm} の$ 円状に面積平均した瞬時の渦度 $\omega$ を算出した (Fig. 5 参照). 左エッジ部での結果と $x_{d} / h$ との比較を Fig. 9 に示す. $\omega の$ 最小值は $x_{d} / h$ の最小值とずれた位置になっており, 気泡形 状，非対称性と同様に，周期的変化をしていることが確認 できた。

\section{5. 結量}

高速・高空間分解能 CCD カメラを用いる事で, 気泡のア スペクト比, 曲率, 重心位置それぞれ互いに周期変動し相 関があることが判った。同様にエッジ部における渦度も， ピーク位置に位相のずれを伴い周期変動した．気泡形状変 化と渦度との相関を調べるためにエトベス数のような気泡 径を考虑したパラメータを用い, 渦度と気泡重心位置のピ 一ク位置に生じた位相のずれを調べる必要があると考えら れる。

\section{6. 考文献}

(1) 柘植 - 日比野, 1971, 化学工学 35-1 pp. 65-71.

(2) Tomiyama, A., Celata, G. P., Hosokawa, S. and Yoshida, S., 2002, Int. J. Multiphase Flow 28, pp. 1497-1519.

(3) Danmoto, Y., Fujiwara, A., Hishida, K.and Maeda, M., 2002, July $8^{\text {th }}-11^{\text {th }}$, Lisbon, Portugal, CD-ROM, 3-5
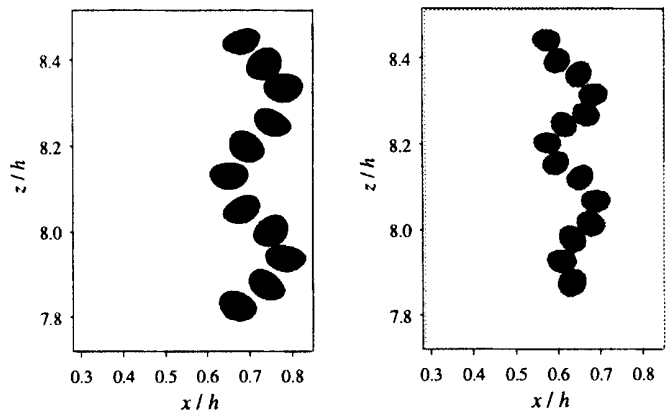

Fig. 3. Examples of bubble trajectory

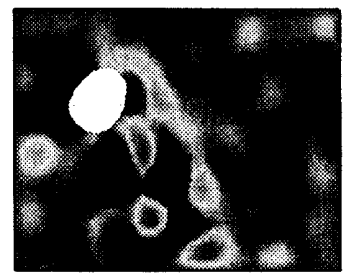

a) Zigzag motion

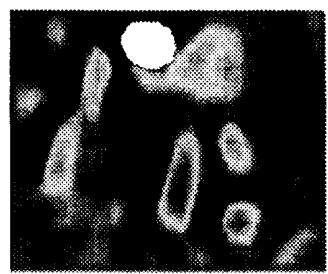

b) Zigzag motion in $y-z$ plane

Fig. 4. Typical snapshot of vorticity contour

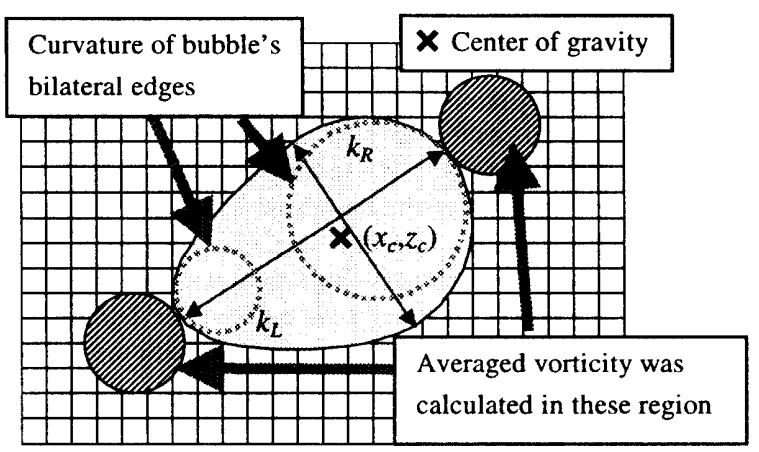

Fig. 5. Construction of curvature $k_{L}, k_{R}$ and averaged vorticity $\omega$

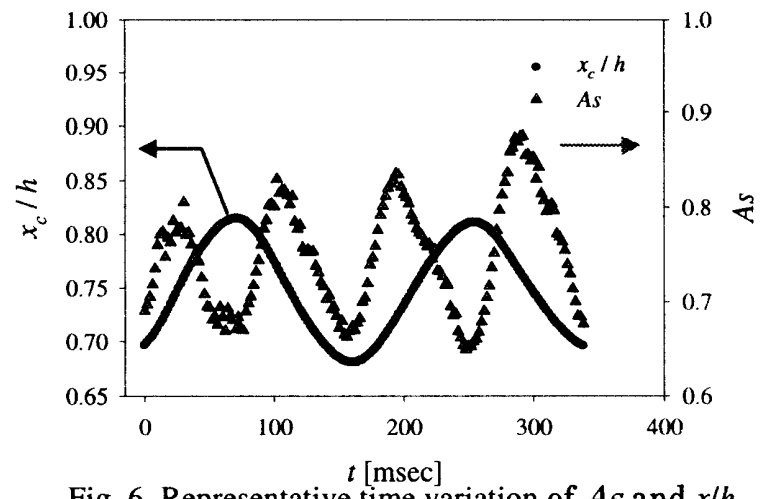

Fig. 6. Representative time variation of $A s$ and $x / h$

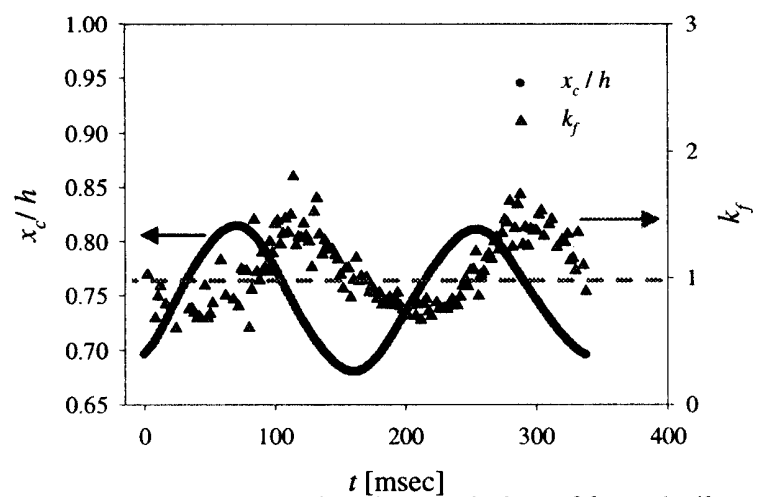

Fig. 7. Representative time variation of $k r$ and $x / h$

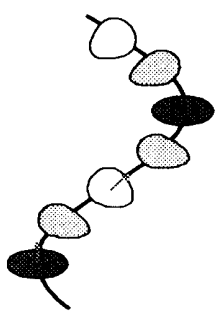

Fig. 8. Variation of bubble's shape

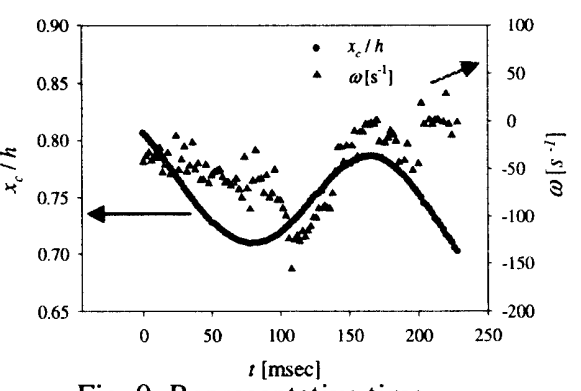

Fig. 9. Representative time variation of $\omega$ and $x / h$ 